\section{Changes in the Lymph Glands of Tumour-Bearing Mice}

DURING experiments in this Institute as previously described ${ }^{1,2,3}$, a spindle-celled sarcoma ( $M$ al. sarcoma 1) was obtained in a mouse after 133 days' treatment with a carcinogenic compound. Mice bearing grafted generations of this tumour showed blood changes to accompany the growth of the grafts, and on five occasions cell-free filtrates giving rise to sarcomas resembling the parent tumour were obtained and grafted for many generations. In the 122nd generation of the original sarcoma, a cell-free filtrate of this tumour, together with blood from the mouse bearing the grafted generation, was introduced into an irradiated mouse, which produced a sarcoma ( $\mathrm{Mal}$. Fil. 6) at the site of inoculation. This tumour and its descendants have provided the material for the experiments to be described.

Mice bearing these tumours show the following changes :

(1) In many, the lymphoid tissue becomes involved in a widespread neoplastic change affecting the glands of axillæ, groin, lumbar and mesenteric regions. The degree of involvement shows no relation to the proximity of the grafted tumour. Microscopic examination of the glands shows four conditions, namely :

(a) The gland may differ little if at all from normal.

(b) Changes similar to those seen in mice after $\mathrm{X}$-radiation, or during induction of a sarcoma by a chemical agent ${ }^{4,5}$.

(c) The lymphoid tissue is more or less wholly replaced by spindle-cells similar to those of the tumour grafts. In these cases, such glands may or may not show enlargement. Minute and remote glands giving no macroscopic evidence of change may be composed of tumour cells. Comparison of sections suggest that this change begins at the periphery, for the medulla may be entirely surrounded by a band of large, pale cells which extend down the trabeculæ in close masses. The appearances do not suggest the spread of these cells from a metastatic focus. They seem rather compatible with some further development of process $(b)$. The simultaneous ehanges in glands on both sides of the body are difficult to explain by any process of metastasis.

(d) The normal lymphoid cells appear to undergo hyperplasia with enlargement of the glands, suggesting a lymphosarcomatous change difficult to explain.

(2) Subcutaneous injections of blood from these mice produce sarcomas-one of which is now in its sixth grafted generation.

(3) Portions of glands, or whole glands from mice hearing grafted generations of Mal. Fil. 6 and other tumours similarly obtained, when grafted into mice, induce tumours at site of inoculation-which sarcomas have been propagated by grafting. In selecting glands for transplantation those appearing to be enlarged were avoided, and, where microscopic examination was made of other halves of glands grafted, many of these appeared normal. Hence the capacity for neoplastic growth on transplantation does not seem to depend on previous sarcomatous changes as described under $1(c)$. It might be suggested that the process of transplantation per se encourages growth ${ }^{6}$. The rapidity of changes involved is remarkable-a lymph gland transferred from mouse $A$ to mouse $B$ five days after grafting the sarcoma in $A$ has been found fifteen days later to have produced a tumour histologically similar to the parent graft in $A$. Normal mice grafted with normal glands have not developed tumours.

Similar results have also been obtained with the mouse sarcoma $S 37$.

The factors concerned in these changes in lymph glands are under investigation here, and quantitative estimations of iron in such glands are being carried out by Mr. Warren. The metabolism of lymph glands is being examined by Mrs. Boyland.

These inquiries have been assisted by grants from the International Cancer Research Foundation, the British Empire Cancer Campaign, and the Finney. Howell Research Foundation.

Research Institute,

\section{Dorothy Parsons.}

The Royal Cancer Hospital (Free), Fulham Road, S.W.3. July 28.

1 Cook, J. W., J. Chem. Soc., 3277 (1931).

Cook, J. W., and Burrows, H., Amer. J. Cancer, 27, 267 (1936).

' Parsons, L. D., J. Path. and Bact., 40, 46 (1935).

- Mayneord, W. V., and Parsons, L. D., ibid., 45, 35 (1937).

${ }^{5}$ Clarkson, J. R., Mayneord, W. V., and Parsons, L. D., ibid., 46, 221 (1938).

'Fischer, A., Amer. J. Cancer, 81, 1 (1937).

\section{Assay of Thyrotropic Hormone}

THE thyroid gland of the grass snake (Tropidonotus natrix) is readily affected by subcutaneous injections of small amounts of thyrotropic hormone, showing hyperplasia and a strong colloid loss. As it presents a very constant histological picture under conditions

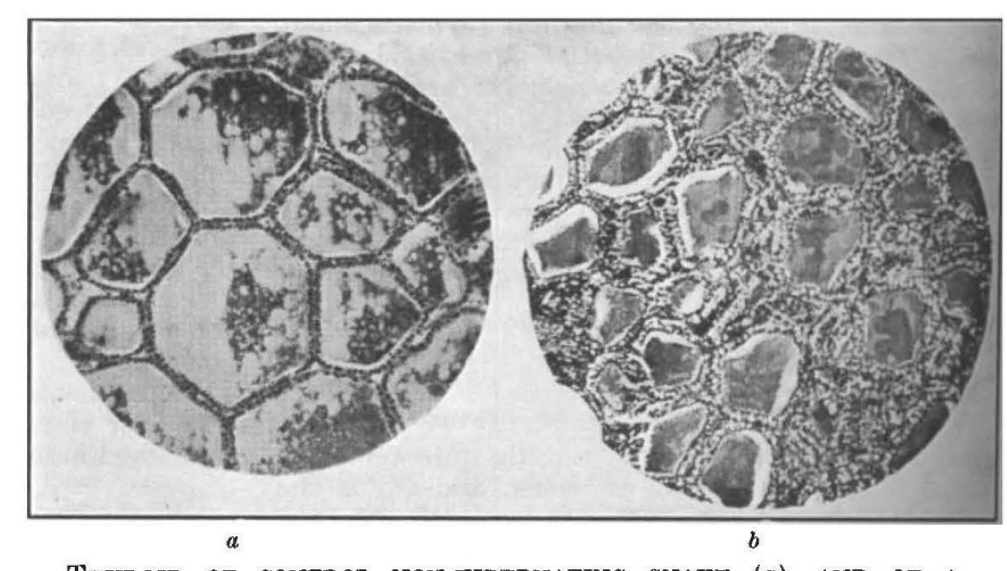

THYROID OF CONTROL NON-HIBERNATING SNAKE (a), AND OF A SIMILAR SNAKE INJECTED WITH THYROTROPIC HORMONE $(b)$.

where the thyroids of animals such as rats and guinea pigs often show considerable histological variation, this is suggested as a possible means of assay of thyrotropic hormone. Although effective at temperatures so low as $13^{\circ} \mathrm{C}$., thyrotropic hormone reacts more strongly at $24^{\circ} \mathrm{C}$. Grass snakes are inexpensive and easily handled in a laboratory. 